
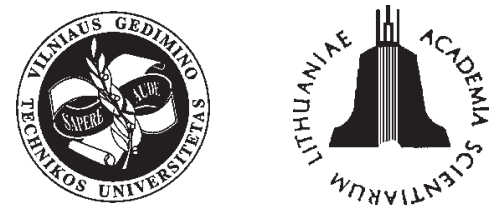

JOURNAL OF CIVIL ENGINEERING AND MANAGEMENT

http:/www.jcem.vgtu.lt

2005, Vol XI, No 4, 251-266

\title{
EXPLOSIVE DAMAGE TO INDUSTRIAL BUILDINGS: ASSESSMENT BY RESAMPLING LIMITED EXPERIMENTAL DATA ON BLAST LOADING
}

\author{
Egidijus Rytas Vaidogas \\ Dept of Reinforced Concrete Structures, Vilnius Gediminas Technical University, \\ Saulètekio al. 11, LT-10223 Vilnius, Lithuania.E-mail: erv@st.vtu.lt
}

Received 19 July 2005; accepted 26 Sept 2005

\begin{abstract}
Assessment of damage to industrial buildings due to accidental explosions in air is considered. It is suggested to formulate the result of the damage assessment in the form of risk. The expression of risk embraces probabilities of foreseeable damage events (damage probabilities) and outcomes (consequences) of suffering these events. The situation is examined when blast loading imposed by an accidental explosion is predicted by a series of experiments. They yield a small-size sample of blast loading characteristics. It is suggested to idealise the formation of explosive damage to industrial buildings by means of event trees diagrams. A quantitative analysis of these diagrams can be carried out by developing fragility functions for their branching points. Each branching point is used to represent a structural failure contributing to the final explosive damage. The fragility functions are applied to expressing the conditional probabilities of explosive damage. With these probabilities, a technique of frequentist (Fisherian) inference is applied to assessing the explosive damage. This technique is called statistical resampling (Efron's bootstrap) and applied as a practical, albeit not equivalent alternative to the Bayesian approaches. It is shown that statistical resampling is capable to yield confidence intervals of damage probabilities and can be applied almost automatically. It operates without using cumbersome methods of statistical inference developed in the classical statistics. The bootstrap confidence intervals do not contain any subjective information except the degree of confidence for which these intervals are computed. The degree of confidence must be chosen by the engineer. The bootstrap confidence intervals are applied to estimating damage probabilities on the basis of the small-size sample of blast loading characteristics. An estimate of the risk of explosive damage is expressed as a set of bootstrap confidence intervals computed for damage probabilities and related outcomes of this damage.
\end{abstract}

Keywords: panel, cladding, explosion, damage, impulsive loading, resampling, bootstrap, simulation, fragility function, vulnerability.

\section{Introduction}

Man-made accidents occurring in industrial facilities are capable of triggering explosions and such accompanying phenomena as fires and impacts by explosion-borne missiles [1]. An explosion induced during man-made accident can be called briefly the accidental explosion (AE; the list of all abbreviations used in this paper is given in Appendix). AEs are well known for their ability to generate blast waves capable to threaten the integrity of structures which are not normally designed to resist explosive actions [2].

Explosive damage can range from simple breakage of windows to total demolition of exposed building. The damage depends on the type of its structures as well as the nature and characteristics of explosion [1]. Structural loading from distant and local explosions depends on the way of how a blast wave is reflected or refracted by exposed structures. Some of them are stiff enough or are supported so that explosive actions will not be influenced by structural behaviour under load. The behaviour of other structures will influence the loading they receive. In the terminology of safety engineering, the former are called the decoupled and the latter the coupled structures [2].

The dynamic loading of a conventional industrial single-storey or multi-storey building from an AE will trigger a sequence of responses of its structures (failures or non-failures). This sequence may result in the damage of various magnitude and character. If the AE occurs outside the building, this damage may be restricted to its envelope or spread inside the building. In a typical industrial building, the sequence of responses will usually be initiated by a failure or a fail-safe response of external cladding panels (wall and roof panels). The cladding panels absorb the energy of external explosion and transfer it, usually through fixing assembles, to the main structure.

The present paper follows the idea that explosive damage to an industrial building should be assessed by 
combining two methodologies. Principles of quantitative risk assessment (QRA, eg, [3]) and structural reliability analysis (SRA, eg, [4]) can be applied to assess likelihood and character of explosive damage. It can be represented as a risk induced by the activity involving the hazard of an AE. The risk can be expressed through probabilities of foreseeable damage events (failures of structural elements exposed to the actions of the AE).

This paper considers how to estimate the probabilities of foreseeable damage events or, in brief, the damage probabilities. The realistic situation of assessing the damage probabilities by means of limited experimental data on blast loading is examined. The data is represented by a small-size statistical sample of pressure signals of an AE. It is suggested to estimate the damage probabilities by applying the method of statistical resampling (Efron's bootstrap) [5-7]. Resampling is used for calculating approximate interval estimates of the damage probabilities.

The mechanical model required for the interval estimation of damage probabilities must be represented in the form of fragility functions (FFs). They should be developed for the damage events of interest. Each FF should relate conditional damage probability versus blast loading imposed by the AE.

\section{Background}

\subsection{Accidental explosions: prediction by means of deterministic models}

Character and magnitude of explosive damage depends on the source and energy of AE. The location of explosion centre with respect to structures of the exposed building is another key factor determining explosive damage. An AE, according to its source, can occur as (i) detonation of explosive charges, (ii) explosion of propellant, dust, gas, and vapour, (iii) bursting of high-energy pressure gas vessels, and (iv) electrical energy discharges $[1,8]$. The character of damage will depend on whether the potential AE is distant explosion (AE producing blast loading which can be considered uniform over faces of the structure), local explosion (AE taking place close to, but not in contact with, the structure), or contact explosion (AE, the exploding charge of which is in direct contact with the structure) [2].

An AE can generate high-speed projectiles (primary and secondary missiles) $[1,2,9]$. The assessment of eventual explosive damage can be complicated by the necessity to account for impacts of these projectiles (see the damage prediction models and references summarised in p. 494 of [10]).

Mathematical models suggested in literature for forecasting pressure signals of AEs are predominantly deterministic. In addition, they are valid only for some fairly ideal conditions. A flat, horizontal ground plane with no obstacles between explosion centre and exposed structure or other target is an example of such conditions (eg,
$[2,8,11])$. It is difficult, if not impossible, to find mathematical models for pressure signal forecasting, where more complex phenomena are involved. For instance, reflections of incident blast wave from adjacent buildings may complicate forecasting of pressure signal [12]. Information on uncertainties related to the mathematical models developed for pressure signal forecasting is, to the best of the author's knowledge, extremely sparse.

Although AEs are rare and difficult-to-predict physical phenomena, each of them is backed by some amount of knowledge (mathematical models, statistical data, and subjective information). This knowledge allows a more or less accurate forecasting of blast loading produced by a particular AE (eg, [13]). Such knowledge can be adopted, with some degree of success, to a particular situation of building exposure to a potential AE. For brevity, this situation will be called the exposure situation.

An assessment of explosive damage in a particular exposure situation is usually a highly case-specific task. Thus, in order to be brief and specific, we focus our attention on a particular type of buildings and AEs. The consideration is confined to single-storey framed buildings (eg, hangars, warehouses, and workshops) and distant AEs in air (ground burst explosions and aboveground explosions).

\subsection{Explosive damage: the dominance of analysis on the element level}

Literature on blast loads induced by distant AEs in air and response of structures to these loads is large and very fragmented. In is beyond the scope of the present paper to systemise this literature. Here, mention can be made of some theoretical and experimental investigations. They range from experiments with individual plated structures (eg, [14-18]) and frames (eg, [19]) to attempts of predicting damage to large structural systems (eg, [20]). Investigations of the damage to plated structures under a combined action of blast loading and missile impact are also reported [21, 22].

Despite the large literature on AEs, we have the strong impression that most investigations are confined to consideration of structural elements, rather than entire buildings. To the best of our knowledge, analytical models suitable to predicting pattern of blast loading exist only for simple, box shaped buildings $[1,2]$. If the exposed building or set of buildings has a complex geometry, it is suggested to assess pattern of blast loading by a scaled or full-scale experiment [23]. This self-evident approach to forecasting blast loading by means of the experiment will be utilised in the subsequent consideration.

The damage to single-storey industrial buildings depends largely on the interaction between building envelope and blast wave of a distant AE. The key elements of the building envelope are cladding panels. Several investigations of explosive action effects on clad- 
ding panels and similar plated structures have been reported so far $[15,24,25]$. Results of these investigations are mainly records of experimental measurements as well as analytical and empirical mathematical models. These models are deterministic. They allow assessing response of cladding panels to explosive actions under given, fixed characteristics of action and exposed structure.

The energy of a distant AE is absorbed by cladding panels transferred to the main structure through fixing assembles. The response of fixings to explosive actions has also attempted attention and some experimental results have been obtained $[16,26]$. However, it seems to be too early to speak about well established deterministic mechanical models of fixing assembles. Thus an analytical, not experimental, predicting of explosive damage to fixing assembles seems to be impossible at present.

Unfortunately and somewhat surprisingly, the works on forecasting explosive damage to structures are, with rare exceptions, free from attempts to quantify uncertainties. Little attention was paid to formal and consistent modelling of uncertainties related to both blast loading and response of structures to it. An exception is investigations carried out by Low and Hao [27, 28]. They are devoted to assessing reliability of reinforced concrete (RC) slabs under explosive actions. These investigations are based on an idealisation of the slabs by a SDOF (single degree of freedom) system. Their results are applicable to a probabilistic prediction of the behaviour of envelope elements exposed to effects of distant AEs.

The papers $[27,28]$ are focussed mainly on an application of deterministic mechanical models to estimating failure probabilities under uncertain characteristics of RC slab. No attention is being paid to a quantification of uncertainty in explosive actions. Probabilities of explosive damage to RC slabs are estimated for fixed values of explosive actions. Thus the work of Low and Hao is, in essence, a fragility study. Results of this study will be applied for solving example problem in Sec 4.5.

A realistic estimation of explosive damage probabilities is hardly possible without appropriate modelling of uncertainty related to explosive actions. Such modelling is far from trivial when one has to deal with rare and difficult-to-predict AEs. We seek to supplement the probabilistic computational models presented in the papers $[27,28]$. It will be demonstrated how to express uncertainties in blast loading by a direct use of a smallsize statistical sample containing pressure signals of an AE.

\subsection{The need of uncertainty modelling}

When it comes to assessing potential explosive damage to a particular building, the structural engineer (analyst) may have to deal with limited knowledge. Usually it is expressed by sparse data on blast loading, if any data is available at all. Another part of this knowledge can be inaccurate mathematical models describing the behaviour of structures under blast loading. In other words, the engineer may face considerable uncertainties related to both blast loading and response of structures to it.

Generally, the more unique (rare) is the exposure situation, the higher are the uncertainties. Classical methods of structural engineering developed for dealing with explosive actions ignore uncertainties by a large margin. Most of them are dominated by deterministic mathematical modelling which does not allow coping with uncertainties in a proper way (eg, textbooks [1, 8], report [13], and structural design code [29]).

A coherent approach to dealing with inevitable uncertainties related to AEs is provided by methodologies of QRA and SRA. In line with the principles of QRA and SRA, the explosive damage should be expressed in terms of probabilities foreseeable damage events. Each damage event is a possible mechanical failure of structural element(s) backed by some mathematical model.

Fundamentally, an estimation of likelihood (frequency or probability) of a potential AE is a QRA problem. It can be extended to assessment of damage due to the AE. This will lead to representing results of damage assessment in the form of risk [30]. The risk can be evaluated by transforming probabilities of damage events into frequencies of these events (eg, [3] for the general definition of risk used in QRA).

QRA developed such logical models as event tree diagrams and fault tree diagrams. They can be used for damage assessment. More specifically, the logical models can serve as a means of a qualitative and quantitative expression of uncertainties related to response of envelope and main structure to blast loading. The risk of explosive damage can be evaluated by a combined application of QRA and SRA methods.

\section{Damage assessment by means of risk analysis}

\subsection{Deriving risk of damage by discretising damage process}

Assessing explosive damage should be preceded by an identification of foreseeable random damage events $D_{i}, i=1,2, \ldots, n_{d}$. Each $D_{i}$ should be understood as exceeding possible limit states, singly or in groups, by structures exposed to AE. For a single-storey framed industrial building, such structures are cladding panels, their fixings and frames supporting the envelope. One of $D_{i}$ s say, $D_{n_{d}}$ can mean the event of no damage (minor damage). In principle, $D_{i} \mathrm{~s}$ can form a set of mutually exclusive and collectively exhaustive random events. The probability of their union, $P\left(\bigcup_{i=1}^{n} D_{i} \mid A E\right)$, will be equal to one. Here the symbol $A E$ denotes the random event of occurrence of an AE.

The stochastic (aleatory) uncertainty in $D_{i} \mathrm{~s}$ can be expressed by the conditional damage probabilities $P\left(D_{i} \mid A E\right)$. With these probabilities, the final result of 
damage assessment can be represented as the set of pairs "damage probability"-“outcome of damage", namely,

$$
\text { Risk } \equiv\left\{\left(P\left(D_{i} \mid A E\right), O_{i}\right), i=1,2, \ldots, n_{d}\right\},
$$

where $O_{i}$ denotes the outcome of the damage $D_{i}$ measured, say, in monetary units. The set (1) is in essence a simplified expression of risk, the general expression of which is presently accepted in QRA [3].

Structural elements of an industrial building are designed to withstand loads acting in the course of its normal use. Resistance of cladding panels and fixings to these loads is verified, as a rule, independently from the main structure. Elements of the main structure (portal frames, say) are also designed independently of one another and of the envelope.

The necessity to estimate the damage probabilities $P\left(D_{i} \mid A E\right)$ will usually require considering envelope and main structure as a whole. Behaviour of the cladding panels and fixings under blast loading can determine the loading received by the main structure. In this regard the behaviour of the system "envelope and main structure" influences the loading it receives. In addition, local damage from the blast wave, say, blown-out windows will also alter the behaviour of structures under blast loading. Consequently, this system can be considered to be a "coupled" structure [2].

The blast wave generated by a distant AE will impose dynamic loads simultaneously on all structural elements of exposed building. The formation of explosive damage from such an AE is a continuous, albeit shortlasting, physical process. However, the risk (1) implies that the scale for measuring damage is discrete rather than continuous. Representing this damage in the form of risk (1) requires discretising the building and damage formation in space and time. This means that the damage should be assessed by carrying out separate, discrete structural analyses. Complexity of the mechanical phenomenon of damage formation provides further impetus for such discretising.

Discretising is an avenue for identifying the damage events $D_{i}$. The definition of each $D_{i}$ should allow estimating the corresponding damage probability $P\left(D_{i} \mid A E\right)$. This means that each $D_{i}$ should be backed by mathematical models suitable for calculating estimates of $P\left(D_{i} \mid A E\right)$.

Attempts to idealise the failure process of complex structures by means of discretising are known in SRA since early 1980s. The key elements of these attempts are logical tree diagrams suggested to reflect possible damage formations in a simplified way. These damage formations are called the "sequences of failure" [31], "cascade failures" [32], "progressive failures" [33]. The tree diagrams, while called by different names, are by their very nature identical to the two main logical models of QRA. Namely, they are either fault tree diagrams or event tree diagrams. The analogues of fault trees are applied in papers [34-36] and the ones of event trees can be found in papers $[31,37]$.
Most of the logical tree diagrams are developed in the framework of the design against progressive collapse. It is a situation in which a localised failure in a structure initiated by an accidental action triggers a cascade of failures affecting a major part of the structure [32, 33]. Approaches developed in an effort to prevent against progressive collapse are directly applicable to local AEs of relatively small energy. Distant AEs are not local phenomena. However, methodological recipes, such as modelling sequences of failures suggested by Bennett [31], can be used for assessing damage from distant AEs.

The logical tree diagrams are suitable to model uncertainty in the possible sequences of failure ending in the damages $D_{i}$. An experimental verification of correctness of these diagrams is usually impossible. Thus the "weapon" against errors in the diagrams remains logical checking.

We hold the viewpoint that the damage from distant AEs should be assessed by a combined application logical event tree modelling and means of SRA. The damage events $D_{i}$ can be identified by developing an event tree diagram. This diagram will represent sequences of responses of structural elements which result in the damage events events $D_{1}, D_{2}, \ldots, D_{n_{d}}$. After the event tree has been constructed, one can start with a quantitative analysis of this model. It should yield estimates of the damage probabilities $P\left(D_{i} \mid A E\right)$.

Standard quantitative techniques of event tree analysis developed in QRA are of little use for the estimation of $P\left(D_{i} \mid A E\right)$ Therefore, we would like to suggests the idea that the probabilities $P\left(D_{i} \mid A E\right)$ can be estimated by constructing FFs for branching points of the event tree diagram which defines the events $D_{i}$.

Developing an event tree related to a specific exposure situation and constructing FFs for its branching points is generally a highly case-specific task. Therefore the consideration given in the following section will be based on an example.

\subsection{Example of logical analysis: event tree modelling of uncertain response to blast loading}

Let us consider the exposure situation shown in Fig 1. The damage to a typical industrial building can be caused by an explosion of stationary process equipment. The location of this equipment with respect to the building is known. However, the characteristics of the blast wave generated by this AE are uncertain and so is the character and magnitude of the explosive damage.

The response of envelope and main structure of the building to blast loading can be idealised as a sequence of random events (failures $E_{k}$ and non-failures $\bar{E}_{k}$, $k=1,2, \ldots)$. An occurrence of some failures $E_{k}$ may essentially change the interaction between remaining, nonfailed structures and blast loading. For example, failure of cladding panels to resist blast loading and transmit it to the main structure results in its unloading. 
(a) Plan of exposure situation

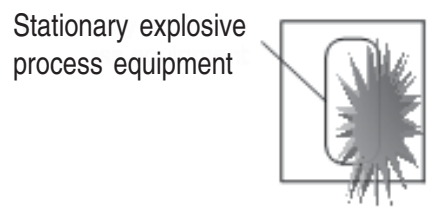

(b) Elevation of exposure situation

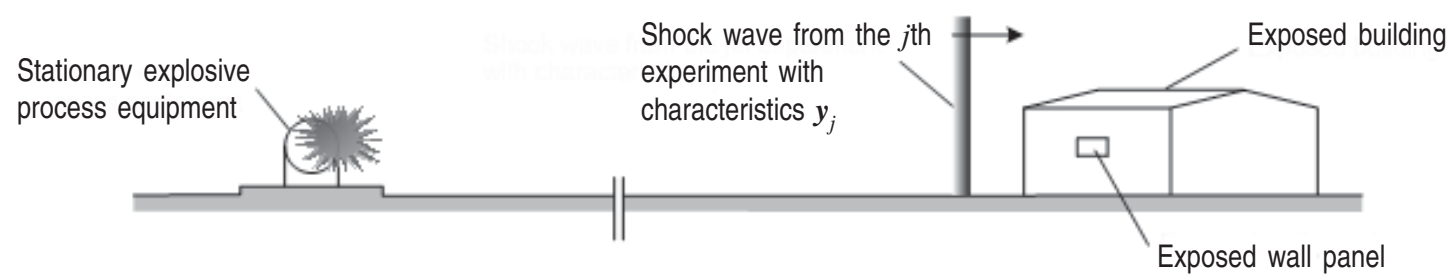

Fig 1. Context of an accidental explosion of dangerous stationary equipment with shock wave characteristics predicted by experiment: (a) plan of exposure situation; (b) elevation of exposure situation

The events $E_{k}$ and $\bar{E}_{k}$ reflect short-lasting mechanical phenomena, the uncertainty in which can be modelled by an event tree diagram. Constructing this diagram should yield the list of damage events $D_{i}$ present in the risk (1). The diagram should be developed at that level of detail which is necessary for the estimation of the damage probabilities $P\left(D_{i} \mid A E\right)$.

Fig 2 shows an example of an event tree diagram with the initiating event $A E$ represented by the vector $\boldsymbol{y}_{j}=\left(y_{1 j}, y_{2 j}, \ldots\right)^{T}$. Components of $\boldsymbol{y} j$ are characteristics of specific pressure signal of the incident blast wave generated by the AE. Typically the components of $\boldsymbol{y}_{j}$ are peak positive overpressure, positive impulse, and positive duration. The vector $\boldsymbol{y}_{j}$ can be measured by triggering an experimental explosion of the process equipment.

The branches of the diagram end in the damage events $D_{1}, D_{2}, \ldots, D_{5}$ and the event of no damage (minor damage) $D_{6}$. It is obvious that the events $D_{i}(i=1$, $2, \ldots, 6)$ can be expressed through the branching events (failures $E_{k}$ and non-failures $\bar{E}_{k}$ ), for instance,

$$
D_{5}=A E \cap \bar{E}_{1} \cap \bar{E}_{3} \cap E_{5} \text {. }
$$

The damage probabilities $P\left(D_{i} \mid A E\right)$ can be represented as products of conditional probabilities of $E_{k} \mathrm{~s}$ and $\bar{E}_{k} \mathrm{~s}$, say,

$$
\begin{aligned}
P\left(D_{5} \mid A E\right) & =P\left(E_{5} \mid \bar{E}_{3} \cap \bar{E}_{1} \cap A E\right) \\
& \times P\left(\bar{E}_{3} \mid \bar{E}_{1} \cap A E\right) \\
& \times P\left(\bar{E}_{1} \mid A E\right) \times 1,
\end{aligned}
$$

where "1" is the probability of $A E$.

Given the event tree diagram in Fig 2, the estimation of the damage probabilities $P\left(D_{i} \mid A E\right)$ amounts to an estimation of the branching probabilities $P\left(E_{k} \mid \cdot\right)$. For a given AE with characteristics $\boldsymbol{y}=\boldsymbol{y}_{j}$, the branching probability $P\left(E_{k} \mid \cdot\right)$ can be calculated by establishing an FF for the failure $E_{k}$. This FF can be represented by the function

$$
F_{k}(\boldsymbol{y})=P\left(E_{k} \mid \ldots \cap(A E \text { with } \boldsymbol{y})\right),
$$

where the expression " $A E$ with $\boldsymbol{y}^{\prime}$ means an occurrence of AE with characteristics $\boldsymbol{y}$. The function $F_{k}(\boldsymbol{y})$ will have the form of a multivariate distribution function (df) if the vector $y$ has more than one component. Generally $F_{k}(y)$ can be constructed by applying standard methods of SRA.

The event tree diagram shown in Fig 2 was constructed to demonstrate the role of FFs in the estimation of the damage probabilities $P\left(D_{i} \mid A E\right)$. This diagram is too general for developing the fragility functions $F_{k}(\boldsymbol{y})$. The events at its branching points, $E_{k}$, are too complex to relate the conditional probabilities of their occurrence, $P\left(E_{k} \mid \cdot\right)$, to the pressure signal characteristics $y$.

A practical estimation of the risk (1) will require defining $E_{k} \mathrm{~s}$ at a sufficiently detailed level. It should make possible developing the fragility functions $F_{k}(\boldsymbol{y})$. Clearly, going into details will influence the risk profile given by the pairs $\left(P\left(D_{i} \mid A E\right), O_{i}\right)$. However, the role of FFs in estimating the damage probabilities $P\left(D_{i} \mid A E\right)$ will remain unchanged, no mater how detailed the event tree diagram is.

\subsection{Fragility functions: the role of structural reliabil- ity analysis in assessing explosive damage}

The functions $F_{k}(y)$ serve for calculating the conditional damage probabilities $P\left(D_{i} \mid \boldsymbol{y}\right)$, that is, probabilities of $D_{i} \mathrm{~s}$ given an AE with the specific characteristics $\boldsymbol{y}$. In essence, each $P\left(D_{i} \mid \boldsymbol{y}\right)$ is also an FF. The difficulty with developing the functions $F_{k}(\boldsymbol{y})$ and $P\left(D_{i} \mid \boldsymbol{y}\right)$ increases generally with increasing dimensionality of $\boldsymbol{y}$.

After FFs have been developed for all failure events $E_{k}$, the functions $P\left(D_{i} \mid \boldsymbol{y}\right)$ can be constructed by multiplying the functions $F_{k}(\boldsymbol{y})$ or $1-F_{k}(\boldsymbol{y})$ related to the ith event tree path. For instance, it follows from Fig 2 


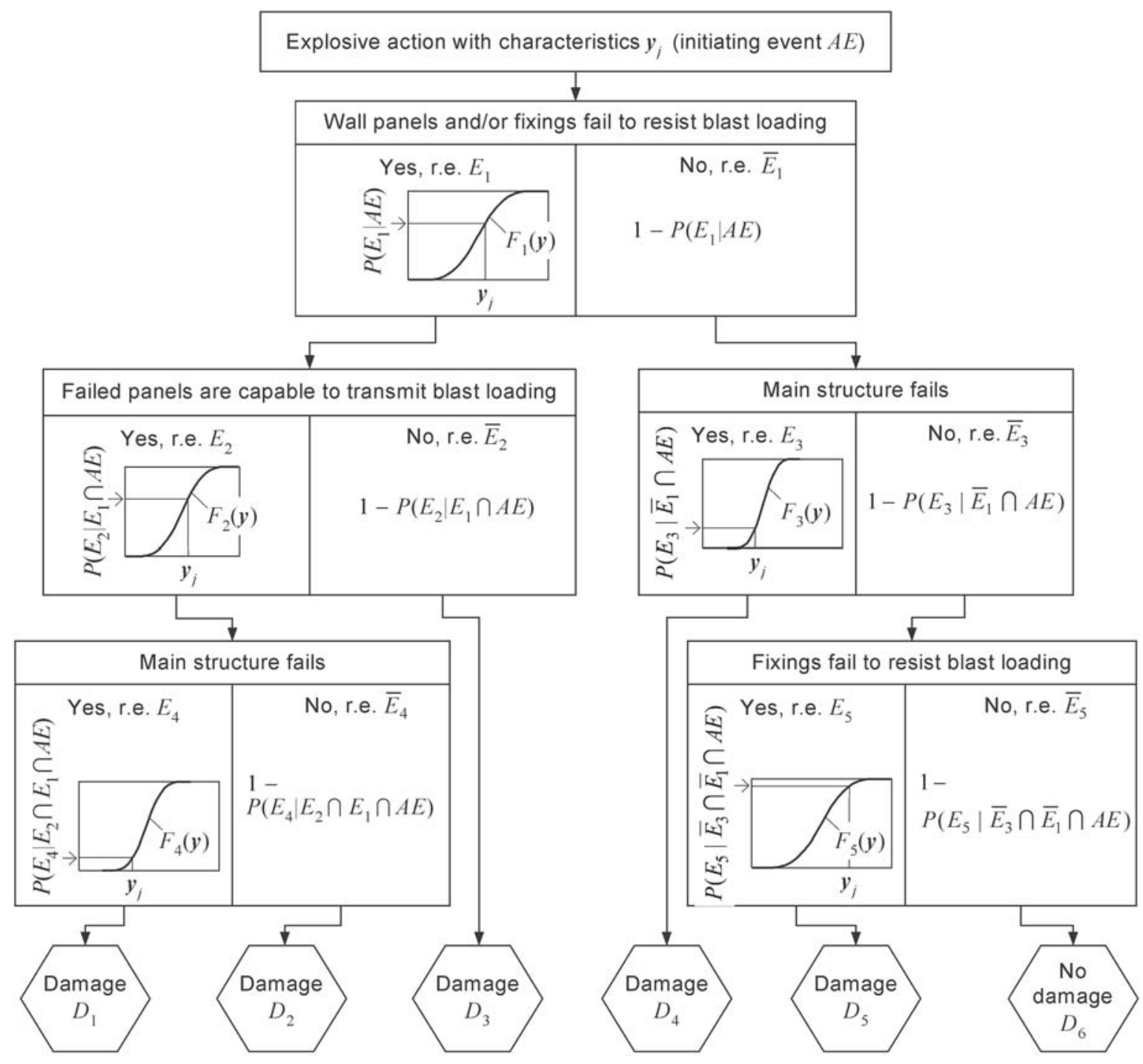

Fig 2. Event tree model depicting simplified scenarios of possible damage to envelope and main structure of building in consequence of an accidental explosion (r.e. = random event)

that the conditional probability $P\left(D_{5} \mid \boldsymbol{y}\right)$ can be written as

$$
P\left(D_{5} \mid \boldsymbol{y}\right)=F_{5}(\boldsymbol{y})\left(1-F_{3}(\boldsymbol{y})\right)\left(1-F_{1}(\boldsymbol{y})\right) \times 1,
$$

where " 1 " is the probability of the AE with characteristics $y$.

With the functions $P\left(D_{i} \mid \boldsymbol{y}\right)$, the estimation of the damage probabilities can be generalised for all possible values of $\boldsymbol{y}$, namely,

$$
P\left(D_{i} \mid A E\right)=\int_{\text {all } \boldsymbol{y}} P\left(D_{i} \mid \boldsymbol{y}\right) \mathrm{d} F_{Y}(\boldsymbol{y})
$$

where $F_{Y}(\boldsymbol{y})$ is the df of the random vector $\boldsymbol{Y}$ which is used to express stochastic uncertainty in the blast wave characteristics.

Although the concept of FF is universal, the main field of application of FFs is the earthquake engineering. FFs are primarily developed for assessing earthquake damage to special types of structures, such as structural parts of nuclear power plants and power transmission systems [38, 39]. Damage to more conventional structures with respect to seismic events is also assessed using FFs [40, 41].

An FF, in its simplest form, quantifies the stochastic uncertainty related to the damage event of interest (eg, [42]). Values of such an FF may be viewed as results of propagating stochastic uncertainty. This FF contains no subjectively assigned information in the form of epistemic (state-of-knowledge) uncertainty measures. This means that the FF can be considered to be purely objective. Most authors, however, introduce subjective (judgmental) elements in FFs. In this way they allow for epistemic uncertainties related to FF values at given argument value (intensity of ground motion characteristic).

Ravindra [43] describes a procedure for developing a family of FFs, each associated with epistemic probability (subjective weight) $w_{k}$. The sum of $w_{k}$ s associated with all FFs is unity. Elements of this procedure are widely used in seismic risk assessment [44]. Sasani et al [45] propose to develop an FF by means of Baye- 
sian parameter estimation. They express epistemic uncertainties in the form of prior and posterior parameter distributions.

All FFs are only intermediate results and epistemic uncertainty measures in them, if available, may be handled in two ways. On the one hand, they can be averaged out prior to estimating the damage probabilities $P\left(D_{i} \mid A E\right)$. On the other, the epistemic uncertainty measures can be further propagated through the relation (2). They will be transformed into distributions of epistemic uncertainty related to true, albeit unknown values of $P\left(D_{i} \mid A E\right)$. However, such distributions are too cumbersome in order to make decisions related to the damage events $D_{i}$. Usually the decisions are made using not the entire uncertainty distribution but some percentiles of it. These percentiles can form intervals of probability values which are similar to confidence intervals calculated in the classical statistics.

Actions generated by AEs are similar to the ones induced by earthquakes. Therefore, approaches to developing FFs used in the field of earthquake engineering are applicable to developing the functions $F_{k}(\boldsymbol{y})$. Despite the natural function of FFs and their wide use to the earthquake engineering, FFs found little if any application to assessing explosive damage. The well-known monographs devoted to explosions and their effects do not even mention the term "fragility function" $[1,2]$.

The possibility to develop the fragility function $F_{k}(y)$ for a specific failure event $E_{k}$ depends mainly on availability of mechanical models describing its occurrence. With these models, the function $F_{k}(\boldsymbol{y})$ can be developed by carrying out a series of SRAs for different values of $\boldsymbol{y}$. Then, depending on the dimensionality of $\boldsymbol{y}$, a univariate or multivariate df can be fitted to results of these SRAs. In this process, SRA serves solely the function of uncertainty propagation. Uncertainties in characteristics of exposed structure are transformed by means of SRA into uncertainties related to the occurrence of $E_{k}$.

Some mechanical models defining $E_{k} \mathrm{~s}$ can be found in the books $[1,2,8]$ and the papers referred to in Sec 2.2. Broadly speaking, the current state of the structural dynamics related to impulsive loads gives grounds for being optimistic about availability of the models describing $E_{k} \mathrm{~s}$. The following presentation assumes that the functions $F_{k}(y)$ can be developed for all $E_{k}$ s identified in a specific damage assessment problem.

The expression (2) is in essence a standard definition of the structural failure probability used in SRA (eg, [4]). The elements of its integrand, $P\left(D_{i} \mid \boldsymbol{y}\right)$ and $F_{Y}(\boldsymbol{y})$, quantify a stochastic uncertainty. This, of course, requires that the values of the function $P\left(D_{i} \mid \boldsymbol{y}\right)$ be measures of the stochastic uncertainty only. If these values are obtained by averaging out epistemic uncertainty measures, the "frequentistic purity" of the result $P\left(D_{i} \mid A E\right)$ will be lost. The probabilities $P\left(D_{i} \mid A E\right)$ will be conditioned on the subjective measures.
If the df $F_{Y}(\boldsymbol{y})$ is available in an explicit form, the expression (2) can be evaluated by means of integration techniques used to SRA. However, a selection of the $\mathrm{df}$ $F_{Y}(y)$ is highly problematic, especially when the vector $\boldsymbol{y}$ has two or more components. Most AEs are rare, unique, and unexpected events. Extracting a sufficiently large sample of the values $\boldsymbol{y}_{j}$ from post-mortem investigations of man-made accidents is hardly possible.

AEs can be imitated by experiment. In this case one can expect that the sample of the observations $\boldsymbol{y}_{j}$ will consists, at best, only of some tens of values. If the experiment is expensive and/or dangerous, the sample of $\boldsymbol{y}_{j}$ s may not exceed ten to twenty observations. Fitting a multivariate df $F_{Y}(\boldsymbol{y})$ to these observations will be difficult.

The central idea of the present paper is that the damage probabilities $P\left(D_{i} \mid A E\right)$ can be estimated by sidestepping the selection of the df $F_{Y}(\boldsymbol{y})$. The probabilities $P\left(D_{i} \mid A E\right)$ and eventually the risk (1) can be evaluated by a direct application of a small-size sample of $\boldsymbol{y}_{j} \mathrm{~s}$. The proposed approach does not require developing the fragility functions $P\left(D_{i} \mid \boldsymbol{y}\right)$ in the form of explicit functions of one or several variables. In contrast, an estimation of values of $P\left(D_{i} \mid \boldsymbol{y}\right)$ for the observations $\boldsymbol{y}_{j}$ is sufficient for assessing the probabilities $P\left(D_{i} \mid A E\right)$.

\section{Procedure of damage assessment by means of boot- strap resampling}

\subsection{Context and idea of the proposed procedure}

Actions from blasts of some kinds of explosives can be predicted by means of deterministic regression models. They relate overpressure and duration (impulse) of an incident blast wave with the so-called scaled distance $[1,2]$. However, these models do not allow drawing any inferences about uncertainties in predictions made by them. What is more, these models are useless when one has to predict pressure signal of explosive, which was not investigated earlier. Potential effects of an explosion of some new dangerous process equipment also can not be assessed by such models. In this context, some experimental work may be necessary to predict pressure signal characteristics $\boldsymbol{y}$. Descriptions of experiments on explosives can be found in literature (eg, [2, 11, 25]).

Experiments on explosions in air yield large amount of empirical information. It includes records of entire pressure signals of experimental explosions. However, an approximate analysis of exposed structures requires only two characteristics of the pressure signal recorded in experiment. These characteristics are peak positive overpressure $y_{1}$ and positive duration $y_{2}$.

The values of $y_{1}$ and $y_{2}$ can be transformed by means of deterministic models into peak positive overpressure $y_{1}^{\prime}$ and duration $y_{2}^{\prime}$ of reflected wave [1]. Components of the vector $\boldsymbol{y}^{\prime}=\left(y_{1}^{\prime}, y_{2}^{\prime}\right)^{T}$ can be used to establish exponentially decaying function of the pressure 
signal of reflected blast wave. According to the investigation [28], this idealised pressure signal is expressed as

$$
\text { Pressure }(t)=y_{1}^{\prime} \exp \left\{-2 t / y_{2}^{\prime}\right\},
$$

where the ratio $2 / y_{2}^{\prime}$ is called the pressure decay rate.

Uncertainties related to the components of the vector $\boldsymbol{y}=\left(y_{1}, y_{2}\right)^{T}$ can be assessed by some number $n$ of experiments. Each of them can imitate an accident inducing AE. Generally the number $\mathrm{n}$ will be relatively small due to expensiveness of experiments on AEs, especially, full-scale experiments.

The series of $n$ experiments can yield the statistical sample

$$
\mathbf{y}=\left\{\boldsymbol{y}_{1}, \boldsymbol{y}_{2}, \ldots, \boldsymbol{y}_{j}, \ldots, \boldsymbol{y}_{n}\right\}
$$

where $\boldsymbol{y}_{j}$ is the value of the vector $\boldsymbol{y}$ observed in the $j$ th experiment.

The use of the sample $\mathbf{y}$ can be the only practical approach to assessing uncertainties related to unique and rare AEs. Clearly, the question of whether $\mathbf{y}$ is a representative sample of some underlying population will always be critical. This question should be answered by a careful consideration of the context and conditions in which the $n$ experiments are carried out.

The small-size sample $\mathbf{y}$ can be directly applied to an estimation of the damage probabilities $P\left(D_{i} \mid A E\right)$. Estimates of $P\left(D_{i} \mid A E\right)$ can be obtained by means of a computer intensive technique known as statistical resampling or bootstrap resampling [5-7]. This technique can be used as an alternative to Bayesian methods which are usually applied in case of sparse statistical information.

\subsection{Searching for alternative to Bayesian approaches}

With the small-size sample $\mathbf{y}$, it is problematic to obtain accurate estimates of the damage probabilities $P\left(D_{i} \mid A E\right)$. An estimation of $P\left(D_{i} \mid A E\right)$ is possible only with some degree of certainty. This certainty can be expressed by quantifying uncertainty in true, albeit unknown and unobservable values of $P\left(D_{i} \mid A E\right)$. This type of uncertainty is called in QRA the epistemic uncertainty. The stochastic uncertainty expressed by the probabilities $P\left(D_{i} \mid A E\right)$ is considered irreducible. The epistemic uncertainty in $P\left(D_{i} \mid A E\right)$ can be reduced by increasing the amount of knowledge on $A E$. First and foremost, increasing the size of the sample $\mathbf{y}$ will contribute to the reduction of the epistemic uncertainty. The use of the two types of uncertainty is adopted in QRA for convenience of mathematical modelling [46].

Here, a QRA measure, namely, the risk (1) is used for expressing the explosive damage. Therefore, it stands to reason to apply QRA methods to quantifying uncertainties in the damage events $D_{i}$. State-of-the-art methods of QRA are based on the Bayesian statistical theory and are called the Bayesian approaches to risk assessment (eg, [47, 48]). As applied to the estimation of the damage probabilities $P\left(D_{i} \mid A E\right)$, these approaches can produce two results. Firstly, they can yield a distribution of epistemic uncertainty in $P\left(D_{i} \mid A E\right)$. Secondly, a point value can be assigned to each $P\left(D_{i} \mid A E\right)$. This value will express the epistemic uncertainty only.

A classical Bayesian approach assumes that there exists a true, objective value of $P\left(D_{i} \mid A E\right)$. The uncertainty in this true value is expressed by means of a random variable $P_{i}$ with an epistemic df $F_{P_{i}}\left(p_{i}\right)$. This df can in theory be updated when new information becomes available. The df $F_{P_{i}}\left(p_{i}\right)$ will quantify subjective confidence of the engineer in the true value of $P\left(D_{i} \mid A E\right)$.

A fully Bayesian (predictive, epistemic) approach is capable to produce point values of $P\left(D_{i} \mid A E\right)$. However, these point values will not be estimates of the true values of $P\left(D_{i} \mid A E\right)$ in the classical statistical sense. The fully Bayesian approach does not presume an existence of true, objective values of $P\left(D_{i} \mid A E\right)$. According to this approach, all probabilities are subjective. The point values of $P\left(D_{i} \mid A E\right)$ will serve as measures of epistemic uncertainty (engineer's subjective confidence in a future occurrence of $D_{i}$ s given $A E$ ).

The results produced by the Bayesian approaches are subjective. An augmentation of the sample $\mathbf{y}$ by new elements $\boldsymbol{y}_{n+1}, \boldsymbol{y}_{n+2}, \ldots$ should, at least in theory, reduce this subjectivity. The data augmentation allows updating the epistemic uncertainty measures, that is, the probability distributions or the point values. It is a very attractive and useful feature of the Bayesian approaches.

The Bayesian approaches fit fairly well methodological demands of QRA. However, their application to assessing explosive damage may be hampered by two stumbling blocks of practical nature:

Firstly, the "Bayesian" situation when the experience in the form of the sample elements $\boldsymbol{y}_{n+1}, \boldsymbol{y}_{n+2}, \ldots$ arrives constantly (a little bit at a time) and allows gradual updating (improving) measures of epistemic uncertainty related to $P\left(D_{i} \mid A E\right)$ is not typical of managing hazards of AEs.

Secondly, the subjectivity of the results produced by the Bayesian approaches may be unacceptable for decision-makers in the traditional field of structural engineering. Many of them have little knowledge of QRA. They can simply require to assess the potential explosive damage only on the basis of "objective“ information available in the from of the sample $\mathbf{y}$.

When the probabilities $P\left(D_{i} \mid A E\right)$ are to be estimated on the basis of the small-size sample $\mathbf{y}$, an equivalent alternative to the Bayesian approaches can hardly be found.

\subsection{Application of statistical resampling to damage probability estimation}

Resampling is a data-based simulation technique for statistical inference without analytical calculation $[5,6]$. It can be applied to assessing damage due to accidental actions in case of limited statistical information on these actions [49]. A use of this technique for assessing the explosive damage can start from representing each of the 
damage probabilities $P\left(D_{i} \mid A E\right)$ in the form of a mean value, namely,

$$
P\left(D_{i} \mid A E\right)=\int_{\text {all } \boldsymbol{y}} P\left(D_{i} \mid \boldsymbol{y}\right) \mathrm{d} F_{\boldsymbol{Y}}(\boldsymbol{y})=E\left(P\left(D_{i} \mid \boldsymbol{Y}\right)\right) .
$$

The expression (4) means that estimating the damage probability $P\left(D_{i} \mid A E\right)$ amounts to estimating the mean of a fictional population of probability values. This population can be described by a random variable $P_{i}$ defined as

$$
P_{i}=P\left(D_{i} \mid \boldsymbol{Y}\right)
$$

Statistical resampling allows drawing statistical inferences about the mean value $E\left(P\left(D_{i} \mid \boldsymbol{Y}\right)\right)$ in a completely automatic way. A sample of realisations of $P_{i}$ necessary for this resampling-based inferring can be created by estimating the conditional damage probabilities $P\left(D_{i} \mid \boldsymbol{y}_{j}\right)$.

If the damage event $D_{i}$ is a complex mechanical phenomenon, the probabilities $P\left(D_{i} \mid \boldsymbol{y}_{j}\right)$ can be expressed though the values $F_{k}\left(\boldsymbol{y}_{j}\right)$ of FFs. An approach described in Secs 3.3 and 3.4 can be applied to calculate the values $P\left(D_{i} \mid \boldsymbol{y}_{j}\right)$. Alternatively, if $D_{i}$ is a relatively simple structural failure, values of $P\left(D_{i} \mid \boldsymbol{y}_{j}\right)$ can be estimated by means of the expressions

$$
P\left(D_{i} \mid \boldsymbol{y}_{j}\right)=\int_{\text {all } z} \mathbf{1}_{i}\left(z, \boldsymbol{y}_{j}\right) \mathrm{d} F_{\boldsymbol{Z}}(z), j=1,2, \ldots, n
$$

and

$$
\mathbf{1}_{i}\left(z, \boldsymbol{y}_{j}\right)=\left\{\begin{array}{l}
1 \text { if } g_{i}\left(z, \boldsymbol{y}_{j}\right) \leq 0\left(\text { damage event } D_{i} \text { occurs }\right) \\
0 \text { otherwise }
\end{array}\right.
$$

where $\boldsymbol{y}_{j}$ is the $j$ th element of the sample $\mathbf{y} ; \boldsymbol{Z}$ is the random vector with the df $F_{Z}(z)$ expressing the stochastic uncertainty in those structural characteristics which are relevant to predicting the damage $D_{i} ; g_{i}\left(z, \boldsymbol{y}_{j}\right)$ is the limit state function (performance function) determining an occurrence of $D_{i}$. Examples of $g_{i}\left(z, \boldsymbol{y}_{j}\right)$ formulated for behaviour of plated structures under explosive loading are presented in the papers $[24,27,28]$.
A set of $n$ estimates $p_{i j}$ of the probability $P\left(D_{i} \mid \boldsymbol{y}_{j}\right)$ will form the sample

$$
\boldsymbol{p}_{i}=\left\{p_{i 1}, p_{i 2}, \ldots, p_{i j}, \ldots, p_{i n}\right\} .
$$

The elements $p_{i j}$ of $\boldsymbol{p}_{i}$ can be treated as realisations of the random variable $P_{i}$. A conventional application of the statistical resampling to estimating the mean $E\left(P\left(D_{i} \mid \boldsymbol{V}\right)\right)$ is based on the sample $\boldsymbol{p}_{i}$. It starts from drawing some number $B$ of bootstrap samples $\mathrm{p}_{i 1}^{\prime}, \mathrm{p}_{i 2}^{\prime}, \ldots$, $\mathrm{p}_{i b}^{\prime}, \ldots, \mathrm{p}_{i B}^{\prime}$ from the original sample $\boldsymbol{p}_{i}$ or its empirical distribution. With the set of bootstrap samples, inferences about $E\left(P\left(D_{i} \mid \boldsymbol{Y}\right)\right)$ can be drawn in the form of interval estimates. They are called the bootstrap confidence intervals (BCIs) for mean. The principle of such estimation and the role of FFs in it is illustrated in Fig 3.

Statistical resampling known also as bootstrap technique or, simply, bootstrap is usually understood as a means of frequentist statistical inference. Consequently, estimates of the damage probabilities $P\left(D_{i} \mid A E\right)$ computed by applying statistical resampling will be fairly objective results of the frequentist inference.

The bootstrap is, however, not a purely frequentist means. There is a Bayesian form of bootstrap or the Bayesian bootstrap [7]. It is a specialised application of bootstrap intended to a simulation of posterior distribution of a population parameter. The Bayesian bootstrap can be applied to the estimation of the probabilities $P\left(D_{i} \mid A E\right)$ within the Bayesian inference [50]. However, the following consideration will be confined to the use of bootstrap for drawing frequentist inferences about $P\left(D_{i} \mid A E\right)$.

\subsection{Bootstrap confidence intervals for probabilities of explosive damage}

Several different techniques for constructing onesided and two-sided BCIs for the population mean have been developed [5]. In principle, each of them can be used to the interval estimation of the damage probabili-

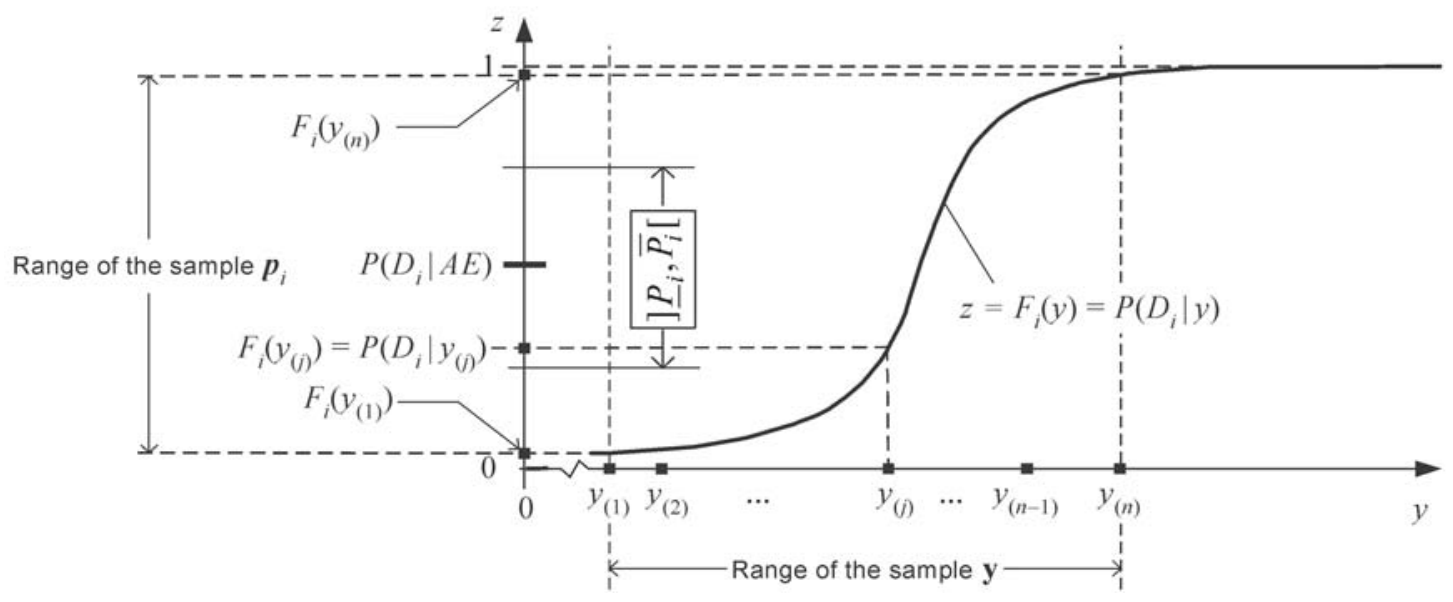

Fig 3. One-dimensional visualisation of transforming the initial sample of AE characteristics, $\mathbf{y}$, into a fictitious sample damage probability estimates, $\boldsymbol{p}_{i}$, related to the damage event $D_{i}$ (the symbols $y_{(1)}, y_{(2)}, \ldots, y_{(j)}, \ldots, y_{(n)}$ denote the ordered one-dimensional sample obtained from $\mathbf{y}$ ) 
ties $P\left(D_{i} \mid A E\right)$. Theoretical and empirical comparison of these techniques is presented in section 5 of the book [6]. This comparison does not allow accepting one technique as the acme among them.

Some techniques (eg, studentized bootstrap and adjusted percentile methods) are more accurate than others (eg, basic bootstrap confidence limit method and percentile methods). However, the more accurate ones require either theoretical derivations or heavy computations. Thus, less accurate but easy-to-use techniques may be useful in practical applications [7]. The interval estimation of $P\left(D_{i} \mid A E\right)$ is such a practical application. It should seek to produce approximate results for decision making, and not to ensure the purity of statistical inference only.

Each technique for constructing BCI yields an interval $] \underline{P}_{i}, \bar{P}_{i}$ [ which approximately covers $P\left(D_{i} \mid A E\right)$ with a given degree of confidence $1-2 \alpha$. That is,

$$
P\left(\underline{P}_{i}<P\left(D_{i} \mid A E\right)<\bar{P}_{i}\right)=1-2 \alpha,
$$

where $2 \alpha$ is called in the classical statistics the risk of erroneous rejection (eg, [51]).

Two BCIs were chosen to illustrate the the interval estimation of the probabilities $P\left(D_{i} \mid A E\right)$. These BCIs are the basic percentile interval and the standard normal interval.

The two-sided percentile interval is given by

$$
] \underline{P}_{i}, \bar{P}_{i}[=] \bar{p}_{B \alpha}, \bar{p}_{B(1-\alpha)}[,
$$

where $\bar{p}_{B \alpha}$ and $\bar{p}_{B(1-\alpha)}$ are the $100 \cdot \alpha$ th and $100 \cdot(1-\alpha)$ th percentiles of the sample $\left\{\bar{p}_{1}, \bar{p}_{2}, \ldots, \bar{p}_{b}, \ldots, \bar{p}_{B}\right\}$. The bth component of this sample, $\bar{p}_{b}$, is the mean of the corresponding bootstrap sample $\mathrm{p}_{i b}^{\prime}$. The values $\bar{p}_{b}$ are called the bootstrap replication of the mean $\bar{p}_{i}$ of the original sample $\boldsymbol{p}_{i}$. For simplicity, the subscript " $i$ " is skipped in some symbols related to the expression (6).

The two-sided standard normal interval is expressed as

$$
] \underline{P}_{i}, \bar{P}_{i}[=] \bar{p}_{i}-z_{1-\alpha} \cdot \hat{s}_{b o o t}, \bar{p}_{i}+z_{1-\alpha} \cdot \hat{s}_{b o o t}[,
$$

where $\bar{p}_{i}$ is the mean of the sample $\boldsymbol{p}_{i} ; z_{1-\alpha}$ is the $1-\alpha$ quantile of the standard normal distribution; $\hat{s}_{\text {boot }}$ is the is the bootstrap standard error (eg, [5], p. 13).

It is natural to use the same degree of confidence, $1-2 \alpha$, for the interval estimation of probabilities of each damage event $D_{i}$. In this case it will be possible to compare probabilities of different $D_{i} \mathrm{~s}$. A BCI can also be computed for the event of no damage, $D_{n_{d}}$, if such event is considered in the analysis. This can be done by estimating the probabilities $P\left(D_{n_{d}} \mid \boldsymbol{y}_{j}\right), j=1,2, \ldots, n$ defined by (5) with $i=n_{d}$ and

$$
\mathbf{1}_{n_{d}}\left(z, \boldsymbol{y}_{j}\right)=\left\{\begin{array}{l}
1 \text { if } g_{i}\left(z, \boldsymbol{y}_{j}\right)>0 \text { for every } i<n_{d} \\
0 \text { otherwise. }
\end{array}\right.
$$

Once the intervals $] \underline{P}_{i}, \bar{P}_{i}$ [ have been computed, the risk of explosive damage given by the set (1) can be reformulated by replacing the unknown damage probabilities $P\left(D_{i} \mid A E\right)$ with the interval estimates $] \underline{P}_{i}, \bar{P}_{i}[$ :

Risk estimate $\equiv\left\{(] \underline{P}_{i}, \bar{P}_{i}\left[, O_{i}\right), i=1,2, \ldots, n_{d}\right\} \cdot(8)$

The resampling-based interval estimation of population means seems to be purely objective (does not require any judgement). However, the particular estimate of risk of explosive damage expressed by the set (8) will be determined by one subjective element, namely, the degree of confidence $1-2 \alpha$. The value of $1-2 \alpha$ should be determined and interpreted before computing the intervals $] \underline{P}_{i}, \bar{P}_{i}[$.

For a given $1-2 \alpha$, the width of $] \underline{P}_{i}, \bar{P}_{i}$ [ will normally decrease with increasing the $n$ size of the sample $\mathbf{y}$. That is, an augmentation of the sample $\mathbf{y}$ by new elements $\boldsymbol{y}_{n+1}, \boldsymbol{y}_{n+2}, \ldots$ will generally result in an updating (decrease) of uncertainty related to the probabilities $P\left(D_{i} \mid A E\right)$. In some sense this updating of the intervals ]$\underline{P}_{i}, \bar{P}_{i}$ [ is similar to a formal updating of epistemic uncertainty distributions in the Bayesian framework.

The good point of the intervals (6) and (7) is that their calculation does not require to develop the entire fragility function $P\left(D_{i} \mid \boldsymbol{y}\right)$. Only an estimation of the relatively small number $\mathrm{n}$ of the probabilities $P\left(D_{i} \mid \boldsymbol{y}_{j}\right)$ is necessary. Generally speaking, the obvious advantage of the BCIs is that they can be computed almost automatically. So the resampling-based interval estimation of the damage probabilities $P\left(D_{i} \mid A E\right)$ do not require any use of engineering judgement.

\subsection{Quantitative example: estimating probabilities of explosive damage to a cladding panel}

Let us return to the exposure situation shown in Fig 1. The explosion of the stationary process equipment can cause damage to the cladding panel on the front face (façade) of the exposed building (Fig 4 a). Probabilities of this damage are to be estimated by means of BCIs.

The load carrying layer of the cladding panel can be idealised as a simply supported, one-way RC slab (Fig $4 \mathrm{~b}$ ). The dimensions of the panel are $3,0 \times 1,0 \times 0,17 \mathrm{~m}$ with $1 \%$ bottom (tension) reinforcement and nominal top reinforcement. Detailed information about the panel is given in Tables 1 and 2 of the paper [28]. The cladding panel is simplified into a SDOF system as given by Low and Hao [28].

The position of the exposed building is known in advance and so is the distance from the explosive equipment (explosion-standoff). A known orientation of the building with respect to the explosion centre allows determining the angle of incidence of the blast wave, $\alpha_{i n c}$ (Fig 4 b).

In this example, the risk of explosive damage is defined as

$$
\text { Risk } \equiv\left\{\left(P\left(D_{i} \mid A E\right), O_{i}\right), i=1,2,3\right\},
$$

where $D_{1}$ is the random event of damage consisting in flexural failure of the panel at mid-span; $D_{2}$ is the ran- 
(a) Plan of exposure situation

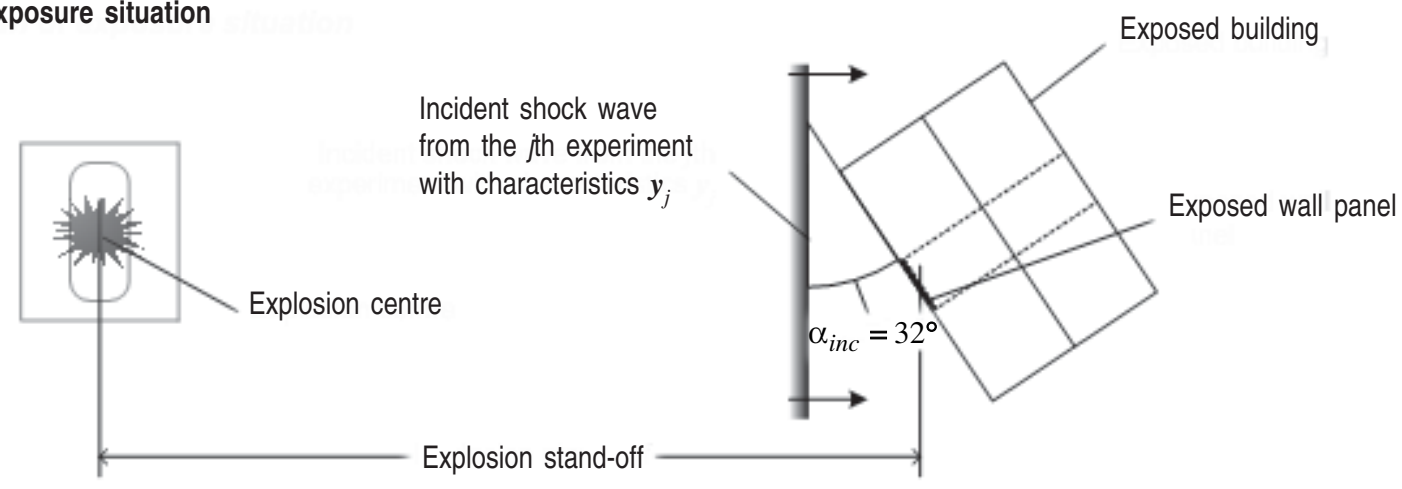

(b) Incident wave \& reflected wave

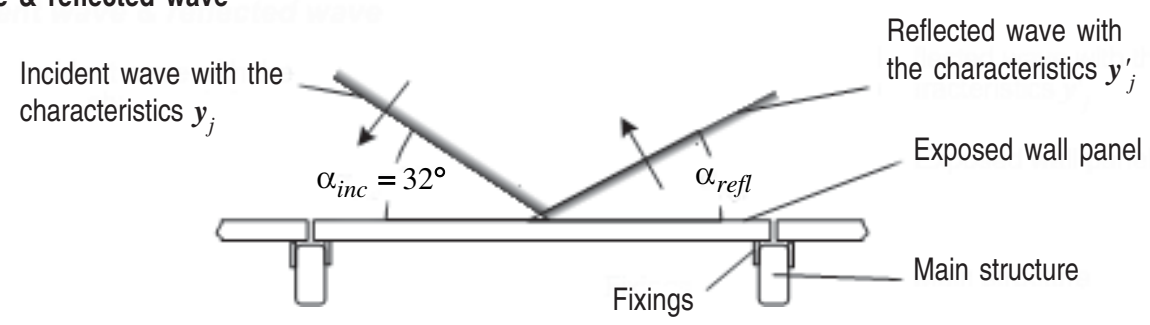

Fig 4. Schematic illustration of reflection of the incident blast wave from a distant explosion by exposed cladding panel $\left(\alpha_{\text {inc }}=\right.$ incidence angle; $\alpha_{\text {refl }}=$ reflection angle $)$

dom event of damage due to shear failure of the panel at its supports; $D_{3}$ is the random event representing all remaining states which the panel can enter in consequence of blast loading. The event $D_{3}$ embraces also the state of no damage. From the definitions of the three $D_{i} \mathrm{~s}$ it is apparent that these events are mutually exclusive and collectively exhaustive events. Consequently, the probability $P\left(D_{1} \cup D_{2} \cup D_{3} \mid A E\right)$ is equal to one.

An occurrence of either $D_{1}$ or $D_{2}$ may bring a sudden change in behaviour of the main structure supporting the RC panels. The events $D_{1}$ and $D_{2}$ may be associated with "blowing-out" panels of a windowless portal frame building, say, a storehouse or a production bay.
The occurrence of $D_{1}$ or $D_{2}$ will allow the blast wave to enter inside the building and alter loading on its internal faces. Horizontal explosive actions received by portal frames will decrease together with the occurrence of $D_{1}$ or $D_{2}$.

Two limit state (performance) functions $g_{1}\left(\boldsymbol{z}, \boldsymbol{y}_{j}^{\prime}\right)$ and $g_{2}\left(\boldsymbol{z}, \boldsymbol{y}_{j}^{\prime}\right)$ will be used to predict the damage events $D_{1}$ and $D_{2}$, respectively. These functions relate maximum responses of the cladding panel to ultimate limits of these responses:

$$
g_{1}\left(\boldsymbol{z}, \boldsymbol{y}_{j}^{\prime}\right)=1-\frac{\delta_{\max }\left(\boldsymbol{z}, \boldsymbol{y}_{j}^{\prime}\right)}{\delta_{u}(\boldsymbol{z})}
$$

Table 1. Sample of 14 values of estimated positive overpressure and duration of reflected blast wave, $\boldsymbol{y}_{j}^{\prime}=\left(y_{1 j}^{\prime}, y_{2 j}^{\prime}\right)^{T}$, and samples of Monte Carlo estimates of probabilities of damage to the cladding panel in consequence of its flexural or shear failure, $p_{1 j}$ and $p_{2 j}$

\begin{tabular}{l|l|l|l|l|l}
\hline$j$ & $y^{\prime}{ }_{1 j}(\mathrm{MPa})$ & $y_{2 j}^{\prime}(\mathrm{msec})$ & $p_{1 j}$ & $p_{2 j}$ & $1-p_{1 j}-p_{2 j}$ \\
\hline 1 & 0,802 & 11,1 & 0,751 & 0,125 & 0,124 \\
\hline 2 & 0,659 & 10,4 & 0,332 & 0,0553 & 0,613 \\
\hline 3 & 0,710 & 13,7 & 0,951 & 0,0159 & 0,0331 \\
\hline 4 & 0,797 & 8,13 & 0,304 & 0,0608 & 0,635 \\
\hline 5 & 0,867 & 6,51 & 0,203 & 0,0472 & 0,750 \\
\hline 6 & 0,641 & 9,04 & 0,206 & 0,0381 & 0,756 \\
\hline 8 & 0,684 & 5,10 & 0,0144 & 0,0040 & 0,982 \\
\hline 9 & 0,753 & 14,6 & 0,971 & 0,0162 & 0,0128 \\
\hline 10 & 0,699 & 9,60 & 0,343 & 0,0602 & 0,597 \\
\hline 11 & 0,622 & 8,82 & 0,150 & 0,0283 & 0,822 \\
\hline 12 & 0,779 & 9,64 & 0,451 & 0,0791 & 0,470 \\
\hline 14 & 0,828 & 9,03 & 0,503 & 0,0931 & 0,404 \\
\hline
\end{tabular}


and

$$
g_{2}\left(z, y_{j}^{\prime}\right)=1-\frac{\vartheta_{\max }\left(z, y_{j}^{\prime}\right)}{\vartheta_{u}}
$$

where $\delta_{\max }\left(z, y_{j}^{\prime}\right)$ is the maximum mid-span displacement; $\vartheta_{\max }\left(z, y_{j}^{\prime}\right)$ is the maximum shear slip at support; $\delta_{u}(z)$ and $\vartheta_{u}$ are the ultimate displacement at the midspan of the panel and the ultimate direct shear slip at the support corresponding to the flexural and shear responses, respectively.

Values of the maximum responses $\delta_{\max }\left(z, y_{j}^{\prime}\right)$ and $\vartheta_{\max }\left(\boldsymbol{z}, \boldsymbol{y}_{j}^{\prime}\right)$ are computed from two loosely coupled motion equations. These equations are formulated for equivalent flexural SDOF system and equivalent shear SDOF system into which the cladding panel is simplified. Analytical solutions of the motion equations are given in paper [28]. Values of the ultimate displacement $\delta_{u}(z)$ are computed using an iterative procedure. The value of the ultimate displacement $\vartheta_{u}$ is assumed to be equal to $0,6 \mathrm{~mm}$ as in the parametric studies carried out by Low and Hao [28].

With the limit state functions (9) and (10), the damage probabilities $P\left(D_{1} \mid y_{j}^{\prime}\right)$ and $P\left(D_{2} \mid y_{j}^{\prime}\right)$ can be expressed as

$$
P\left(D_{1} \mid \boldsymbol{y}_{j}\right)=P\left(1-\frac{\delta_{\max }\left(\boldsymbol{Z}, \boldsymbol{y}_{j}^{\prime}\right)}{\delta_{u}(\boldsymbol{Z})} \leq 0\right), j=1,2, \ldots, n
$$

and

$$
P\left(D_{2} \mid \boldsymbol{y}_{j}\right)=P\left(1-\frac{\vartheta_{\max }\left(\boldsymbol{Z}, \boldsymbol{y}_{j}^{\prime}\right)}{\vartheta_{u}} \leq 0\right), j=1,2, \ldots, n .
$$

The values $P\left(D_{1} \mid y_{j}^{\prime}\right)$ and $P\left(D_{2} \mid y_{j}^{\prime}\right)$ were estimated for the sample of reflected blast wave characteristics given in Table 1. The sample consists of 14 vectors $\boldsymbol{y}_{j}^{\prime}=\left(y_{1 j}^{\prime}, y_{2 j}^{\prime}\right)^{T} \quad(n=14)$. These sample elements were calculated from the peak positive overpressure $y_{1}$ and positive duration $y_{2}$ of the pressure signal of incident blast wave measured in an experiment with 14 explosions of the stationary process equipment. Components of the vector $\boldsymbol{y}_{j}^{\prime}$ were estimated from components of the experimental vector $\boldsymbol{y}_{j}=\left(y_{1 j}, y_{2 j}\right)^{T}$ using deterministic models relating characteristics of incident and reflected blast waves and given, for instance, in [1]. All 14 explosions that yielded the measurements $\boldsymbol{y}_{j}$ were carried out using nominally identical units of the equipment.
A stochastic simulation was used to compute the probabilities $P\left(D_{1} \mid y_{j}^{\prime}\right)$ and $P\left(D_{2} \mid y_{j}^{\prime}\right)$ for all 14 values of $\boldsymbol{y}_{j}^{\prime}$. So the simulation yielded two samples of probability estimates, $\boldsymbol{p}_{1}=\left\{p_{11}, p_{12}, \ldots, p_{1,14}\right\}$ and $\boldsymbol{p}_{2}=\left\{p_{21}\right.$, $\left.p_{22}, \ldots, p_{2,14}\right\}$. These samples are given in Table 1. In terms of statistical resampling $\boldsymbol{p}_{1}$ and $\boldsymbol{p}_{2}$ are called the original samples.

The BCIs used for estimating the damage probabilities $P\left(D_{1} \mid A E\right)$ and $P\left(D_{2} \mid A E\right)$ were calculated by generating 1000 independent bootstrap samples $\boldsymbol{p}_{11}^{\prime}, \boldsymbol{p}_{12}^{\prime}, \ldots$, $\boldsymbol{p}_{1,1000}^{\prime}$ and $\boldsymbol{p}_{21}^{\prime}, \boldsymbol{p}_{22}^{\prime}, \ldots, \boldsymbol{p}_{2,1000}^{\prime}$, that is, $B=1000$. Each pair of samples $\boldsymbol{p}_{1 b}^{\prime}$ and $\boldsymbol{p}_{2 b}^{\prime}$ was obtained by drawing with replacement (resampling) random samples of size $n=14$ from the original samples $\boldsymbol{p}_{1}$ and $\boldsymbol{p}_{2}$, respectively (see the books $[5,6]$ for technical details of resampling). Along with this resampling, mean values $\bar{p}_{1 b}$ and $\bar{p}_{2 b}$ of the bootstrap samples $\boldsymbol{p}_{1 b}^{\prime}$ and $\boldsymbol{p}_{2 b}^{\prime}$ $(b=1,2, \ldots, 1000)$ were computed.

The BCIs are computed using the samples of the mean values,

and

$$
\overline{\boldsymbol{p}}_{1}=\left\{\bar{p}_{11}, \bar{p}_{12}, \ldots, \bar{p}_{1,1000}\right\}
$$

$$
\overline{\boldsymbol{p}}_{2}=\left\{\bar{p}_{21}, \bar{p}_{22}, \ldots, \bar{p}_{2,1000}\right\} .
$$

Table 2 summarises values of the two-sided $90 \%$ BCIs, $] \underline{P}_{i}, \bar{P}_{i}[(i=1,2,3)$, computed using the methods (6) and (7) for the samples $\overline{\boldsymbol{p}}_{1}$ and $\overline{\boldsymbol{p}}_{2}$. The bootstrap intervals obtained using the normal approximation method (7) are, strictly speaking, incorrect. The samples $\overline{\boldsymbol{p}}_{1}$ and $\overline{\boldsymbol{p}}_{2}$ cannot be considered to be ones from a normal population. This is illustrated in Fig 5, where normal densities are fitted to the histograms of $\overline{\boldsymbol{p}}_{1}$ and $\overline{\boldsymbol{p}}_{2}$. Negative results of Shapiro-Wilk test reject the normality of $\overline{\boldsymbol{p}}_{1}$ and $\overline{\boldsymbol{p}}_{2}$. In spite of the results shown in Fig 5, the confidence intervals based on the normal approximation (7) are very close to ones computed using bootstrap percentile method (6).

Table 2 contains also values of the one-sided $90 \%$ BCIs, ]0, $\bar{P}_{i}[(i=1,2,3)$. The one-sided percentile interval and the one-sided standard normal interval were calculated using the respective formulas

and

$$
] 0, \bar{P}_{i}[=] 0, \bar{p}_{B \times 0.9}[
$$

\begin{tabular}{|c|c|c|c|c|}
\hline \multirow{3}{*}{ Damage events } & \multicolumn{4}{|c|}{ Confidence intervals calculated by the method of } \\
\hline & \multicolumn{2}{|c|}{ Bootstrap percentiles } & \multicolumn{2}{|c|}{ Normal approximation } \\
\hline & Two-sided & One-sided & Two-sided & One-sided \\
\hline $\begin{array}{l}\text { Damage due to flexural failure } \\
\text { of cladding panel (event } D_{1} \text { ) }\end{array}$ & ] 0,$3434 ; 0,6132[$ & ] 0;0,5873[ & ] 0,$3432 ; 0,6172[$ & ] $0 ; 0,5869[$ \\
\hline $\begin{array}{l}\text { Damage due to shear failure of } \\
\text { cladding panel (event } D_{2} \text { ) }\end{array}$ & ] 0,03462;0,06655 [ & ] $0 ; 0,06338[$ & ] 0,$03491 ; 0,06671[$ & ] $0 ; 0,06319[$ \\
\hline $\begin{array}{l}\text { Other damage or no damage to } \\
\text { cladding panel (event } D_{3} \text { ) }\end{array}$ & ] 0,$3264 ; 0,6003[$ & ] 0;0,5791[ & ] 0,$3300 ; 0,6034[$ & ] $0 ; 0,5732[$ \\
\hline
\end{tabular}

$$
\text { ]0, } \bar{P}_{i}[=] 0, \bar{p}_{i}+z_{0.9} \cdot \hat{s}_{\text {boot }}[,
$$

where $B=1000$.

Table 2. Bootstrap confidence intervals with $90 \%$ degree of confidence used to estimate the probabilities $P\left(D_{1} \mid A E\right), P\left(D_{2} \mid A E\right)$ and $P\left(D_{3} \mid A E\right)$ 
In some cases there may be sense in using the onesided upper intervals $] 0, \bar{P}_{i}$ [ although the two-sided ones are preferable with respect to accuracy. For instance, the decision-maker may pay attention only to large values of $P\left(D_{1} \mid A E\right)$ and $P\left(D_{2} \mid A E\right)$. In other words, he may have interest only in the results $P\left(D_{1} \mid A E\right)<\bar{P}_{2}$ and $P\left(D_{2} \mid A E\right)<\bar{P}_{2}$ and not in the possibility of $P\left(D_{1} \mid A E\right)<\underline{P}_{1}$ and $P\left(D_{2} \mid A E\right)<\underline{P}_{2}$. The decision-maker may also be interested in a non-exceedance of some tolerable values of $P\left(D_{1} \mid A E\right)$ and $P\left(D_{2} \mid A E\right)$. This nonexceedance may be indicated by the results $P\left(D_{i} \mid A E\right)<\bar{P}_{i} \quad(i=1,2)$, where $\bar{P}_{i}$ the limit of the onesided upper interval.

The use of the one-sided intervals allows sidestepping the problem which arises with an unacceptably large length $\bar{P}_{i}-\underline{P}_{i}$ of the two-sided intervals. Lastly, it is very simple to incorporated limits of the upper one-sided intervals into expression of risk (1).

The two-sided BCIs given in Table 2 cover $27 \%$, $3,2 \%$ and $28 \%$ of possible probability values, respectively. It can be considered to be narrow enough, especially if we recall that these intervals were obtained using only 14 measurements of pressure signal. The BCIs allow constructing the risk estimate defined by (8) and they are final result of this example.

\section{Conclusions}

Assessment of damage to industrial buildings due to accidental explosions (AEs) in air has been considered. It was suggested to formulate the result of the damage assessment in the form of risk. The expression of risk embraces probabilities of foreseeable damage events (damage probabilities) and outcomes (consequences) of suffering these events. The situation was considered when blast loading imposed by an AE is predicted by a series of experiments. They yield a small-size sample of blast loading characteristics.

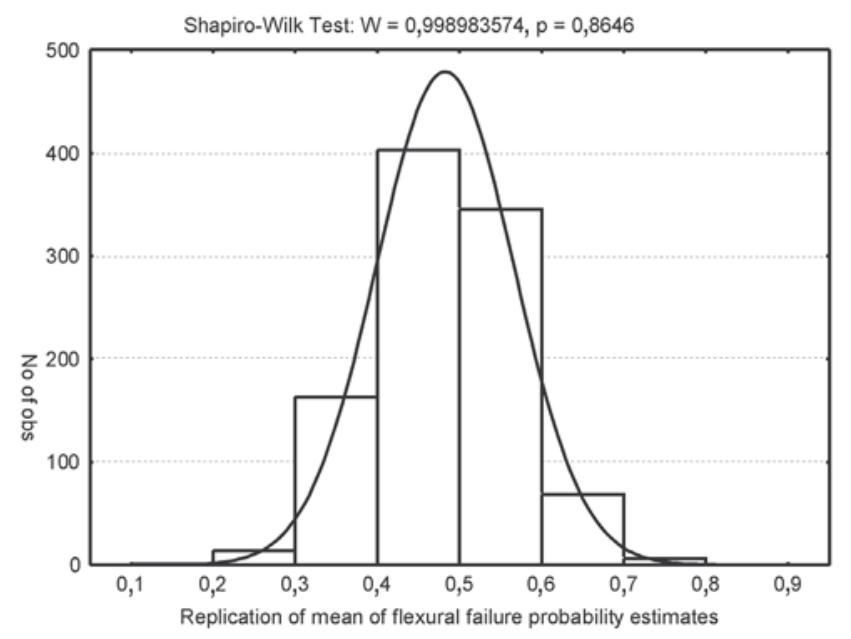

It was suggested to idealise the formation of explosive damage to industrial buildings by means of event trees diagrams. A quantitative analysis of these diagrams can be carried out by developing fragility functions for their branching points. Each branching point represents a structural failure contributing to the final explosive damage. At present, there exist mechanical models which allow developing fragility functions for relatively simple damage events. However, the concept of the fragility function is universal and, in theory, it can be developed for complex, real-world structural failures induced by AEs.

The fragility functions can be applied to expressing the conditional probabilities of explosive damage. With these probabilities, various techniques of statistical inference can be used to assessing the risk of explosive damage. In this paper, a technique of frequentist (Fisherian) inference was applied to assessing the explosive damage.

At first, an application of Bayesian approaches to assessing the risk of explosive damage was analysed in brief. The suitability of Bayesian approaches for dealing with limited statistical information represented by the small-size sample of blast loading characteristics was recognized. At the same time, it was argued that assessing explosive damage in the Bayesian framework can be impracticable. Bayesian approaches produce highly subjective estimates of damage probabilities. This subjectivity can be unacceptable to decision-makers.

A practical, albeit not equivalent alternative to the Bayesian approaches is the so-called statistical resampling (Efron's bootstrap). It is a computer intensive technique of statistical inference. This technique is capable to yield confidence intervals of damage probabilities and can be applied almost automatically. It can be applied without using cumbersome methods of statistical inference developed in the classical statistics. The bootstrap confidence intervals do not contain any subjective informa-

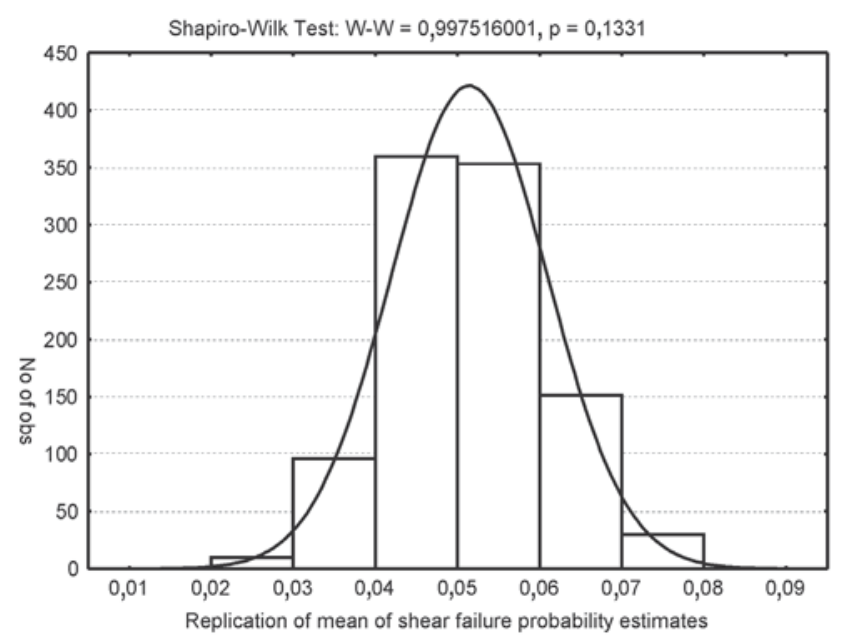

Fig 5. Histograms of samples $\overline{\boldsymbol{p}}_{1}$ and $\overline{\boldsymbol{p}}_{2}$ with fitted normal densities and results of application of Shapiro-Wilk test (eg, [50]) for normality: (a) histogram of 1000 of replications of the mean of 14 estimates of flexural failure probability; (b) histogram of 1000 of replications of the mean of 14 estimates of shear failure probability 
tion except the degree of confidence for which these intervals are computed. The degree of confidence must be chosen by the engineer.

The bootstrap confidence intervals were applied to estimating damage probabilities on the basis of the smallsize sample of blast loading characteristics. However, the intervals were computed using not this initial sample but a statistical sample of equal size containing damage probability estimates. Each of them was computed by estimating the damage probability of interest for corresponding element of the initial sample. The sample of damage probability estimates was considered to be drawn from a fictional population of probability values. The interval estimation of damage probabilities was formulated as drawing statistical inferences about the mean of this population.

An estimate of the risk of explosive damage can be expressed as a set of bootstrap confidence intervals computed for damage probabilities and related outcomes of this damage. An example has shown that the technique of statistical resampling produces confidence intervals of damage probabilities, which are narrow enough from the practical standpoint.

\section{References}

1. Baker, W. E. et al. Explosion hazards and valuation. Amsterdam etc: Elsevier, 1983. 432 p.

2. Bulson, P. S. Explosive loading on engineering structures. London etc: E \& FN Spon, 1997. 236 p.

3. Kumamoto, H.; Henley, E. J. Probabilistic risk assessment for engineers and scientists. $2^{\text {nd }}$ ed. New York etc: IEEE Press, 1996. 597 p.

4. Melchers, R. E. Structural reliability analysis and prediction. $2^{\text {nd }}$ ed. Chichester et al: Wiley, 1999. 449 p.

5. Efron, B.; Tibshirani, R. J. An introduction to the bootstrap. London, New York: Chapman \& Hall, 1993. 436 p.

6. Davisdon, A. C.; Hinkley, D. V. Bootstrap methods and their application. Cambridge: Cambridge University Press, 1998. 582 p.

7. Shao, J.; Tu, D. The jackknife and bootstrap. New York: Springer, 1995. $516 \mathrm{p}$.

8. Tedesco, J. E. et al. Structural dynamics. Theory and applications. Melno Park, California: Addison Werley, Longman Inc., 1999. 707 p.

9. Altwood, G. J.; Kendall, K. C. Methods for the assessment of hazards from free-flying missiles. In: Structures under Shock and Impact II, Ed P. S. Bulson, London: Thomas Telford, 1992, p. 3-14.

10. Twisdale, L. A.; Vickery, P. J. Extreme wind risk assessment. In: Probabilistic Structural Mechanics Handbook, Ed C. (Raj) Sundararajan, New York etc: Chapman \& Hall, 1995, p. 465-509.

11. Wharton, R. K. et al. Airblast TNT equivalence for a range of commercial blasting explosives. Journal of Hazardous Materials, Vol 79, Issues 1-2, 2000, p. 31-39.

12. Watson, A. J. The response of civil engineering structures to impulsive loads. In: Structures under Shock and Impact
III, Ed P. S. Bulson, Ashurst: Computational Mechanics Publications, 1994, p. 3-10.

13. OTI 92595 The prediction of the pressure loading on structures resulting from an explosion. Health and Safety Executive - Offshore Technology Information. London: HMSO Publications Centre, 1992. 28 p.

14. Louca, L. A. et al. Non-linear analysis of blast walls and stiffened panels subjected to hydrocarbon explosions. Journal of Constructional Steel Research, Vol 37, Issue 2, 1996, p. 93-113.

15. Ramajeyathilagam, K. et al. Non-linear transient dynamic response of rectangular plates under shock loading. International Journal of Impact Engineering, Vol 24, Issue 10, 2000, p. 999-1015.

16. Pan, Y. G.; Watson, A. Interaction between concrete cladding panels and fixings under blast loading. Cement and Concrete Composites, Vol 18, Issue 5, 1996, p. 323-332.

17. Duranovic, N.; Watson, A. J. Impulsive loading on reinforced concrete slabs - blast loading function. In: Structures under Shock and Impact III, Ed P. S. Bulson, Ashurst: Computational Mechanics Publications, 1994, p. 63-70.

18. Pan, Y.; Watson, A. J. Effect of panel stiffness on resistance of cladding panels to blast loading. Journal of Engineering Mechanics, Vol 124, Issue 4, 1998, p. 414-421.

19. Cai, G. Q.; Lin, Y. K. Reliability of nonlinear structural frame under seismic excitation. Journal of Engineering Mechanics, Vol 124, Issue 8, 1998, p. 852-856.

20. Lucioni, B. M. et al. Analysis of building collapse under blast loads. Engineering Structures, Vol 26, Issue 1, 2003, p. $63-71$.

21. Forsén, R.; Nordström, M. Damage to reinforced concrete slabs due to the combination of blast and fragment loading. In: Structures under Shock and Impact II, Ed P. S. Bulson, London: Thomas Telford, 1992, p. 139-146.

22. Nordström, M.; Forsén, R. Damage to reinforced concrete slabs due to fragment loading with different fragment velocities, fragment areal densities and sizes of fragments. In: Structures under Shock and Impact III, Ed P. S. Bulson, Ashurst: Computational Mechanics Publications, 1994, p. 131-138.

23. Bailly, P. et al. Accidental explosions near buildings, methodology of the valuation of the effects. In: Structural Safety and Reliability, Proc of ICOSSAR'93, Ed G. I. Schueller, M. Shinozuka, J. T. P. Jao, Rotterdam: Balkema, 1994, p. 1929-1932.

24. Pan, Y.; Watson, A. Effect of panel stiffness on resistance of cladding panels. Journal of Engineering Mechanics, Vol 124, Issue 4, 1998, p. 414-421.

25. Jacinto, A. C. et al. Experimental and computational analysis of plates under air blast loading. International Journal of Impact Engineering, Vol 25, Issue 10, 2001, p. 927947.

26. Pan, Y. G. et al. Transfer of impulsive loading on cladding panels to the fixing assemblies. International Journal of Impact Engineering, Vol 25, Issue 10, 2001, p. 949-964.

27. Low, H. Y.; Hao, H. Reliability analysis of reinforced concrete slabs under explosive loading. Structural Safety, Vol 23, Issue 2, 2001, p. 157-178.

28. Low, H. Y.; Hao, H. Reliability analysis of direct shear 
and flexural failure of RC slabs under explosive loading. Engineering Structures, Vol 24, Issue 2, 2002, p. 189-198.

29. ENV 1991-2-7:1998. Eurocode 1: Basis of design and actions on structures. Part 2-7: Accidental actions due to impact and explosions. Brussels: CEN, 1998. 38 p.

30. Vaidogas, E. R. Probabilistic framework for assessing risks to structures stemming from accidental explosions. Journal of Civil Engineering and Management, Vol VIII, No 2, 2002, p. 108-116.

31. Bennett, R. M. Formulations for probability of progressive collapse. Structural Safety, Vol 5, Issue 1, 1988, p. 67-77.

32. Gross, J. L.; McGuire, W. Progressive collapse resistant design. Journal of Structural Engineering, Vol 109, Issue 1, 1983, p. 1-15.

33. Blandford, G. E. Review of progressive failure analyses for truss structures. Journal of Structural Engineering, Vol 123, Issue 2, 1997, p. 122-129.

34. Feng, Y. Enumerating significant failure modes of a structural system by using criterion methods. Computers \& Structures, Vol 30, Issue 5, 1988, p. 1153-1157.

35. Pinto, J.; Blockley, D.; Woodman, N. The risk of vulnerable failure. Structural Safety, Vol 24, Issues 2-4, 2002, p. $107-122$.

36. Agarwal, J.; Blockley, D.; Woodman, N. Vulnerability of structural systems. Structural Safety, Vol 25, Issue 3, 2003, p. 263-286.

37. Bjerager, P.; Karamchandani, A.; Cornell, C. A. Failure tree analysis in structural reliability. In: Reliability and Risk Analysis in Civil Engineering, Proc of ICASP5, Ed N. C. Lind, Waterloo: University of Waterloo, Vol 2, 1987, p. 985-996.

38. Ellingwood, B. R. Issues related to structural aging in probabilistic risk assessment of nuclear power plants. Reliability Engineering \& System Safety, Vol 62, Issue 3, 1998, p. 171-183.

39. Hwang, H. M.; Huo, J.-R. Seismic fragility analysis of electric substation equipment and structures. Probabilistic Engineering Mechanics, Vol 13, Issue 2, 1998, p. 107-116.

40. Kim, S.-H.; Shinozuka, M. Development of fragility curves of bridges retrofitted by column jacketing. Probabilistic Engineering Mechanics, Vol 19, Issues 1-2, 2004, p. 105 112.

41. Schotanus, M. I. J.; Franchin, P.; Lupoi, A.; Pinto, P. E. Seismic fragility analysis of 3D structures. Structural Safety, Vol 26, Issue 4, 2004, p. 421-441.
42. Vanzi, I. Seismic reliability of electric power networks: methodology and applications. Structural Safety, Vol 18, Issue 4, 1996, p. 311-327.

43. Ravindra, M. K. Seismic risk assessment. In: Probabilistic Structural Mechanics Handbook, Ed C. (Raj) Sundararajan, New York etc: Chapman \& Hall, 1995, p. 429-464.

44. Ellingwood, B. R. Earthquake risk assessment of building structures. Reliability Engineering \& System Safety, Vol 74, Issue 3, 2001, p. 251-262.

45. Sasani, M.; Der Kiureghian, A.; Bertero, V. V. Seismic fragility of short period reinforced concrete structural walls under near-source ground motions. Structural Safety, Vol 24, Issues 2-4, 2002, p. 123-138.

46. Winkler, R. L. Uncertainty in probabilistic risk assessment. Reliability Engineering and System Safety, Vol 54, Issues 23, 1996, p. 127-132.

47. Nilsen, T.; Aven, T. Models and model uncertainty in the context of risk analysis. Reliability Engineering and System Safety, Vol 79, Issue 3, 2003, p. 309-317.

48. Aven, T.; Pörn, K. Expressing and interpreting the results of quantitative risk analyses. Reliability Engineering and System Safety, Vol 61, Issues 1-2, 1998, p. 3-10.

49. Vaidogas, E. R. Statistical resampling in assessing external threats to structures. In.: Proc of PSAM7-ESREL'04. Ed C. Spitzer, U. Schmocker, V. N. Dang, Vol 5, London: Springer, 2004, p. 2920-2925.

50. Vaidogas, E. R. Bayesian bootstrap: Use for estimating probabilities of accidental damage to structures. In: Advances in safety and reliability, Proc ESREL 2005, Ed K. Kołowrocki, Vol 2, Leiden etc: Balkema, 2005, p. 19731980.

51. Sachs, L. Angewandte Statistik. Anwendung statistischer Methoden. 6. Ausg. Berlin etc: Springer, 1984. 552 S. (in German).

\section{Abbreviations used in the paper}

$$
\begin{array}{ll}
\mathrm{AE} & =\text { accidental explosion } \\
\mathrm{BCI} & =\text { bootstrap confidence interval } \\
\mathrm{df} & =\text { distribution function } \\
\mathrm{FF} & =\text { fragility function } \\
\mathrm{QRA} & =\text { quantitative risk assessment } \\
\mathrm{RC} & =\text { reinforced concrete } \\
\mathrm{SDOF} & =\text { single degree of freedom } \\
\text { SRA } & =\text { structural reliability analysis }
\end{array}
$$

\section{SPROGIMU巳 SUKELIAMŲ PRAMONINIŲ PASTATŲ PAŽAIDŲ VERTINIMAS ATLIEKANT KARTOTINI RIBOTŲ EKSPERIMENTINIŲ DUOMENŲ APIE SPROGIMŲ APKROVAS ĖMIMĄ}

\section{E. R. Vaidogas}

\section{Santrauka}

Pramoninių pastatų pažaidų, kurios gali būti sukeltos avarinių (atsitiktinių) sprogimų, vertinimą siūloma formuluoti rizikos skaičiavimo uždavinio pavidalu. Ši rizika aprépia nuspejamų atsitiktinių pažaidų i̇vykių tikimybes (pažaidų tikimybes) ir padarinius, kurie gali būti patirti, pasireiškus šiems i̇vykiams. Nagrinèjamas atvejis, kai pažaidas reikia prognozuoti atliekant nedidelį skaičių kartotinių eksperimentų ir gaunant santykinai mažą statistinę sprogimo apkrovų imtị. Pažaidas siūloma vertinti idealizuojant jų kilimo procesą naudojant ịvykių medžio diagramas. Teigiama, kad skaičiuoti galima kiekvienam diagramos išsišakojimui sudarant pažeidžiamumo funkcijas. Kiekvienas išsišakojimas turi vaizduoti konkrečią pažaidą. Pažeidžiamumo funkcijos taikomos sąlyginėms pažaidų tikimybėms išreikšti. İvertinus šias tikimybes, 
besąlygines pažaidų tikimybes siūloma vertinti kartotinio statistinio ėmimo metodu. Jis laikomas vertinimo, pagrịsto Bèjeso statistinès teorijos metodais, alternatyva. Kartotinis statistinis èmimas leidžia skaičiuoti besąlyginių pažaidų tikimybiu pasikliautinuosius intervalus. Taikant ši metodą, galima išvengti sudètingų klasikinès matematinès statistikos procedūrų taikymo. Skaičiuojant pasikliautinuosius intervalus kartotinio statistinio ėmimo būdu išvengiama subjektyvios informacijos. Inžinieriui tereikia priimti subjektyvų sprendimą, koki pasikliautinumo lygmeni naudoti skaičiuojant pasikliautinuosius intervalus. Parodyta, kad šiuos intervalus galima skaičiuoti net kai statistine sprogimo apkrovų imtis yra maža. Sprogimų sukeliamą riziką siūloma išreikšti pasikliautinaisiais pažaidų tikimybių intervalais.

Raktažodžiai: plokšte, apdaras, sprogimas, pažaida, impulsinė apkrova, kartotinis statistinis emimas, stochastinis modeliavimas, pažeidžiamumo funkcija.

Egidijus Rytas VAIDOGAS. Assoc Prof of Structural Engineering at the Dept of reinforced concrete structures of VGTU. Assoc Prof, 2000, Doctor (structural engineering), 1994. Member of IABSE since 2000. His actual research interests include assessment of reliability of structures and application of methods of quantitative risk assessment to the design of structures. 